\title{
A relevância da técnica de questionamento socrático na prática Cognitivo-Comportamental
}

\author{
The relevance of the Socratic questioning technique \\ in Cognitive-Behavioral practice \\ La relevancia de la técnica de diálogo socrático \\ en la práctica Cognitivo-Conductual \\ Camila Elidia Messias dos SANTOS ${ }^{1}$ \\ Francisco de Assis MEDEIROS ${ }^{2}$
}

${ }^{\text {I} M e s t r a n d a, ~ P r o g r a m a ~ d e ~ P o ́ s-G r a d u a c ̧ a ̃ o ~ e m ~ P s i c o l o g i a ~ d o ~ D e s e n v o l v i m e n t o ~ e ~ A p r e n d i z a g e m, ~}$

Faculdade de Ciências de Bauru, Universidade Estadual Paulista "Júlio de Mesquita Filho", UNESP, 17033-360, Bauru - SP, Brasil

${ }^{2}$ Psicólogo. Pós-graduando em Psicologia e Saúde, Faculdade de Odontologia,

Universidade Estadual Paulista "Júlio de Mesquita Filho", UNESP, 16015-050, Araçatuba - SP, Brasil

\section{Resumo}

A Terapia Cognitivo-Comportamental se constitui como uma abordagem de psicoterapia breve, estruturada e orientada para a solução de problemas. Esse modelo terapêutico utiliza-se de princípios fundamentais de que as cognições exercem influência controladora sobre as emoções e os comportamentos; e o modo de agir ou se comportar podem influir nos padrões de pensamentos e emoções. Apontado como essencial para o andamento das sessões em terapia cognitivocomportamental, o questionamento socrático representa uma das principais técnicas para modificação de pensamentos automáticos. A utilização de tal técnica deve ser feita a partir da identificação e registro dos pensamentos disfuncionais e do encorajamento do paciente a avaliá-los por meio de perguntas que o levem a pensar, e dessa forma, e ter verdadeira compreensão na tomada de decisões racionais segundo suas próprias conclusões. Desta forma, paciente e terapeuta fazem juntos um exame das evidências que apoiam seu pensamento e das evidências que são contrárias, de modo a encontrar novas possibilidades na interpretação de suas sensações físicas. Assim, este artigo tem por objetivo apresentar a aplicabilidade de tal técnica no manejo clínico da terapia cognitivo-comportamental, descrever o envolvimento entre paciente e terapeuta e expor estratégias para as formulações de perguntas; realizando-se em seguida uma discussão sobre suas possíveis indicações, contraindicações, benefícios e desvantagens.

Descritores: Terapia Cognitiva; Atuação (Psicologia); Técnicas Psicológicas.

\begin{abstract}
Cognitive-Behavioral Therapy is a brief, structured and problem-oriented approach to psychotherapy. This therapeutic model uses the fundamental principles that cognitions exert a controlling influence on emotions and behaviors. The way you act or behave can influence the patterns of thoughts and emotions. Aimed as essential for the course of sessions in cognitive-behavioral therapy, Socratic questioning represents one of the main techniques for automatic thinking modification. The use of such technique should be done, from the identification and registration of the dysfunctional thoughts and the encouragement of the patient to evaluate them, through questions that lead him to think, and in this way, and have true understanding in the decision making and their own conclusions. In this way, the patient and therapist together make an examination of the evidences that support their thinking and of the evidence that is contrary, in order to find new possibilities in the interpretation of their physical sensations. Thus, this article aims to present the applicability of such a technique in the clinical management of cognitive-behavioral therapy, to define it, to describe the involvement between the patient and the therapist, and to present strategies for formulating questions; Followed by a discussion of their possible indications, contraindications, benefits and disadvantages.
\end{abstract}

Descriptors: Cognitive Therapy; Acting Out; Psychological Techniques.

\section{Resumen}

La terapia cognitivo-conductual se constituye como un enfoque de la psicoterapia breve, estructurada y orientada a la resolución de problemas. Este modelo terapéutico utiliza los principios fundamentales que las cogniciones ejercen un poder de control sobre las emociones y la conducta; y la forma de actuar o comportarse puede influir en los patrones de pensamientos y emociones. Identificado como esencial para el progreso de las sesiones de terapia cognitivo-conductual, el diálogo socrático es una de las principales técnicas para modificar los pensamientos automáticos. El uso de esta técnica debe realizarse, a partir de la identificación y registro de los pensamientos disfuncionales y el aliento del paciente para su evaluación mediante preguntas que te llevan a pensar, y de esa manera, y tienen cierto conocimiento en la toma de decisiones racional de acuerdo a sus propias conclusiones. Por lo tanto, el paciente y el terapeuta juntos hacen un examen de la evidencia para apoyar su forma de pensar y la evidencia de que son contrarios, con el fin de encontrar nuevas posibilidades en la interpretación de las sensaciones físicas. Por lo tanto, este artículo tiene como objetivo presentar la aplicabilidad de esta técnica en el manejo clínico de la terapia cognitivo-conductual, definirlo, describir la participación entre el paciente y el terapeuta y exponer las estrategias a las formulaciones de preguntas; a continuación, llevar a cabo un análisis de las posibles indicaciones, contraindicaciones, ventajas y desventajas.

Descriptores: Terapia Cognitiva; Actuación (Psicología); Técnicas Psicológicas.

\section{INTRODUÇÃO}

A Terapia Cognitivo-Comportamental (TCC) constitui-se como uma abordagem de psicoterapia breve, estruturada e orientada para a solução de problemas ${ }^{1}$. Esse modelo terapêutico utiliza-se de princípios fundamentais de que as cognições exercem influência controladora sobre as emoções e os comportamentos; e o modo de agir ou se comportar podem influir nos padrões de pensamentos e emoções $^{2}$. Em vista disso, Beck ${ }^{3}$ declara que a visão teórica da TCC está alicerçada na ideia de que tanto os sentimentos como os comportamentos do indivíduo são determinados pelo modo como ele concebe o mundo e suas cognições.

Do mesmo modo, Knapp ${ }^{4}$ afirma que as distorções cognitivas são configuradas a partir de vieses sistemáticos, ou seja, um modo peculiar de como os indivíduos 
interpretam suas experiências. Se a situação é avaliada erroneamente, essas distorções podem amplificar o impacto das percepções falhas. Logo, a reestruturação de um estilo menos enviesado de pensamento pode reduzir a angústia ou dar uma maior sensação de bem-estar².

Assim, a TCC visa através de procedimentos sistemáticos buscar o reconhecimento dos pensamentos disfuncionais, para posteriormente contrastar com seu modo de vida, isto é, procura alterar o sistema das crenças disfuncionais que se encontram subjacentes a essas interpretações enviesadas ${ }^{5}$.

Segundo a abordagem de Beck $^{3}$, nos problemas psicológicos do processamento de informações, não ocorrerem somente uma distorção cognitiva, mas também, uma rigidez, "concretização", de forma a tornar os julgamentos absolutos e generalizados e as crenças fundamentais mais inflexíveis. Sendo assim, os processos básicos da TCC vão além de identificar, examinar e modificar as distorções cognitivas, eles tentam tornar os pensamentos mais flexíveis e não-absolutos, a partir da avaliação dos eventos pelo próprio paciente ${ }^{4}$.

No entanto, a TCC não quer encobrir problemas reais. À vista disto, quando ocorre de uma pessoa estar passando por dificuldades substanciais, busca-se o planejamento e a prática de estratégias de enfrentamento, através de utilização de métodos cognitivos e comportamentais adequados à situação ${ }^{2}$.

Para que isso ocorra é necessário o "empirismo colaborativo", termo utilizado para retratar a relação terapêutica no qual terapeuta e paciente trabalham juntos e em parceria, objetivando checar a realidade e a validade de suas cognições, caracterizadas por pensamentos automáticos, pressupostos intermediários e crenças nucleares, bem como o papel ativo de cada um neste processo ${ }^{6}$.

Ambos, paciente e terapeuta, compartilham a responsabilidade pelo estabelecimento de agenda e cumprimento de metas, mediante oferta e recebimento de feedback relativo as experiências cotidianas, e do desenvolvimento prático dos métodos da $\mathrm{TCC}^{2}$. Buscam ainda incentivar o desenvolvimento e a aplicação de processos conscientes adaptativos de pensamento, a partir da solução de problemas e de pensamento racional ${ }^{2,7,8}$.

Posto isso, uma das finalidades da TCC consiste em corrigir as distorções cognitivas que estão gerando sofrimento ao indivíduo e fazer com que o mesmo desenvolva meios eficazes para enfrentá-los 9 .

Para alcançar tais alterações cognitivas, o primeiro passo consiste em identificar os pensamentos automáticos, utilizando-se qualquer uma das inúmeras técnicas da TCC, entre elas: "reconhecimento das mudanças de humor, psicoeducação, descoberta guiada, registro de pensamentos disfuncionais (RPD), exercícios de imagem mentais, exercícios de role play e uso de inventários"2. Posteriormente, pode-se realizar uma análise dos erros cognitivos peculiares às interpretações catastróficas. No entanto, é importante que o paciente considere tais pensamentos como meras hipóteses, e não como fatos ${ }^{10}$.

Deste modo, a utilização do RPD juntamente com outras técnicas, conduz a atenção do paciente para cognições importantes e proporciona um método sistemático e concreto para praticar a identificação de pensamentos automáticos, estimulando constantemente o inquérito sobre a veracidade dos padrões destes ${ }^{2}$.

Posteriormente, visa-se a modificação das distorções através do direcionamento do pensamento do paciente para uma forma mais adaptativa, que pode ser por meio do "questionamento socrático, uso de registros de mudança de pensamento, geração de alternativas racionais, identificação de erros cognitivos, exame das evidências, descatastrofização, reatribuição, ensaio cognitivo e uso de cartões de enfrentamento",2.(p.78)

Porém, ainda segundo os mesmos autores, o questionamento socrático representa a principal técnica para modificação de pensamentos automáticos, em virtude do processo de inquerir, indispensável para intervenção cognitiva na mudança dos erros de lógica.

Nessa premissa, ao invés de debater ou confrontar as cognições disfuncionais, o terapeuta guia o paciente para a descoberta (por meio de investigação, questionamento com respostas livres, utilizando-se do mesmo modo como era o ensino de Sócrates) de forma a orientar o paciente para que ele entenda seu problema, explore possíveis soluções e desenvolva um plano para lidar com as dificuldades. Ou seja, o terapeuta não dispõe de soluções ou convence o paciente da incorreção dos pensamentos ${ }^{4}$.

Corroborando os dados acima, Beck et al. ${ }^{7}$ salientam que o maior propósito da terapia cognitiva é elucidar o indivíduo através de dados objetivos, e não de convencer o paciente segundo a força dos argumentos.

Assim, a terapia cognitivo-comportamental não é caracterizada por uma intervenção homogênea totalmente padronizada; ao contrário, ela adota várias estratégias singulares combinadas e empregadas com um grupo diversificado de clientes, levando-se em consideração as diferentes idades, o desenvolvimento cognitivo, linguístico e social do indivíduo ${ }^{11}$.

No entanto, existe outra forma de questionamento socrático com igual intuito, chamada de descoberta guiada, essa técnica tenciona através de perguntas indutivas do terapeuta revelar padrões disfuncionais do pensamento ou comportamento do paciente ${ }^{2}$. O objetivo é trazer informações a consciência do paciente, relacionando o pensamento automático com suas consequentes emoções e comportamentos $^{12}$.

Assim, perguntas simples como "o que poderia acontecer então?”, e “ e, então?” Proporcionam a condução do processo por parte do terapeuta, de modo que o paciente evoque e identifique os pensamentos disfuncionais, os pressupostos e esquemas, propiciando desta forma a descoberta dos significados idiossincráticos que o mesmo concede em cada situação ${ }^{12}$.

Este artigo tem por objetivo apresentar a aplicabilidade de tal técnica no manejo clínico da terapia cognitivo-comportamental, descrever o envolvimento entre paciente e terapeuta e expor estratégias para as formulações de perguntas; realizando-se em seguida uma discussão sobre suas possíveis indicações, contraindicações, benefícios e desvantagens.

- Técnica do questionamento socrático

Apontado como essencial para o andamento das sessões em terapia cognitivo-comportamental, o uso do questionamento socrático se destina a identificação de problemas e ao direcionamento de metas, que devem sempre ser planejadas e centradas firmemente na linha do questionamento $^{2}$.

Os terapeutas cognitivistas costumeiramente usam algumas questões básicas ou suas variações para ajudar os pacientes no ponderamento de seus pensamentos ${ }^{13}$. As perguntas realizadas são direcionadas ao paciente com propósito de estimular a curiosidade e o desejo de indagar, proporcionando que o mesmo seja envolvido no processo de aprendizagem $^{2}$. 
A utilização de tal técnica deve ser feita segundo a identificação e registro dos pensamentos disfuncionais e do encorajamento do paciente a avaliá-los, por meio de perguntas que o levem a pensar, e dessa forma, ter verdadeira compreensão na tomada de decisões racionais, segundo suas próprias conclusões ${ }^{14}$.

Desta forma, paciente e terapeuta fazem juntos um exame das evidências que apoiam seu pensamento e das evidências que são contrárias ao seu pensamento, de modo a encontrar novas possibilidades na interpretação de suas sensações físicas.

Ao se utilizar o modo guiado do questionamento, o terapeuta maximiza o envolvimento do paciente nas sessões e em todo o processo terapêutico de modo a reduzir a possibilidade de o terapeuta impor suas ideias e conceitos. Ademais, essa formulação socrática pretende que o paciente aprenda a entender e solucionar seus problemas, equipandose com as habilidades necessárias para lidar com eventuais problemas que possam vir a ocorrer ${ }^{4}$.

Entretanto, com o aumento das habilidades de solução de problemas por parte do paciente, o terapeuta se desvia mais ativamente em guiar o tratamento, proporcionando assim que paciente se torna seu próprio terapeuta. Isso acontece devido ao processo colaborativo da descoberta guiada, em que o paciente sai da posição passiva e adota uma postura proativa ${ }^{4}$.

o Estratégias para a formulação de perguntas no questionamento socrático

Ao utilizar o questionamento socrático para a modificação dos pensamentos automáticos, os terapeutas devem levar em consideração as seguintes estratégias abaixo na elaboração de perguntas ${ }^{2}$ (p.86).

$>$ Faça perguntas que revelem oportunidades de mudança. As boas perguntas socráticas geralmente abrem um leque de possibilidades, desta forma, tente fazer perguntas que ajudem os pacientes a repararem no quanto a modificação do pensamento pode reduzir emoções dolorosas ou melhorar sua capacidade de enfrentamento.

$>$ Faça perguntas que tragam resultados. As melhores perguntas socráticas ocorrem quando rompem um padrão de pensamento desadaptativo rígido e apresentam aos pacientes alternativas razoáveis e produtivas. Ou seja, quando são desenvolvidas novas percepções, e a modificação do pensamento institui uma mudança emocional positiva. Se seu questionamento socrático parecer não estar produzindo qualquer resultado emocional ou comportamental, deve-se revisar a formulação de caso e consequentemente sua estratégia.

$>$ Faça perguntas que envolvam os pacientes no processo de aprendizagem. Como o propósito de ajudar os pacientes a se especializarem em "pensar sobre o pensamento". As perguntas do questionamento socrático devem estimular a curiosidade dos pacientes e incentivá-los a olharem a partir de novas perspectivas. Possibilitando assim que o paciente possa fazer perguntas a si mesmos.

$>$ Elabore perguntas de forma que seja produtivo para o paciente. Formule perguntas que sejam um desafio suficiente para fazer com que o paciente pense, mas que não o faça sentir-se pressionado ou intimidado, assim deve-se levar em consideração o nível de funcionamento cognitivo, os sintomas e a capacidade de concentração do paciente, com o intuito de fazer com que o mesmo tenha boas chances de ser capaz de responder.

$>$ Evite fazer perguntas de comando. Não se deve usar o questionamento socrático como um meio hierárquico entre paciente e terapeuta, mas sim como um método para aumentar a capacidade de o paciente pensar de maneira flexível e criativa. (Certamente, você terá alguma ideia sobre onde o questionamento socrático pode levar e quais resultados você espera obter, mas faça perguntas que respeite a capacidade de os pacientes pensarem por si mesmos. Deixe os pacientes responderem as perguntas sempre que possível).

$>$ Use perguntas de múltipla escolha. O bom questionamento socrático é feito de perguntas abertas, de forma a permitir um grande número de respostas ou mudanças nas respostas. Embora as perguntas do tipo sim ou não ou de múltipla escolha possam ser eficazes em algumas ocasiões, a maioria das perguntas socráticas devem deixar espaço para várias respostas.

o Exemplos da aplicabilidade do questionamento socrático

Um exemplo do uso do questionamento socrático para modificação de crença pode ser analisado abaixo. No diálogo apresentado, ao ocorrer a identificação da crença geral, o terapeuta ajuda o paciente a avaliá-la no contexto de situações especificas, de forma a tornar a avaliação mais concreta e significativa e menos intelectual. Entretanto, essa técnica também pode ser utilizada para identificação de pensamentos automáticos ${ }^{15}$.

A letra $\mathrm{T}$ empregada significa a fala do terapeuta, passa a ser a letra $\mathrm{P}$ a fala do paciente, consecutivamente.

"T: [resumindo o que aprenderam com a recémconcluída técnica de seta descendente] Ok, então você acredita em torno de $90 \%$ que, se pedir ajuda, isso significará que você é incompetente. É isso mesmo? P: Sim.

T: Poderia haver alguma outra forma de encarar um pedido de ajuda?

P: Não estou certa.

T: Considere a terapia, por exemplo. Você é incompetente porque veio buscar ajuda aqui?

P: Um pouco, talvez.

$\mathrm{T}$ : Humm. Isso é interessante porque geralmente eu vejo isso de forma oposta. É possível que na verdade seja um sinal de força e competência o fato de você ter vindo à terapia? O que teria acontecido se não tivesse vindo?

P: Eu ainda estaria puxando as cobertas e tapando a cabeça.

T: Você estaria sugerindo que pedir ajuda adequada quando você tem uma doença como a depressão é uma coisa mais competente a ser feita do que permanecer deprimida?

P: É....acho que sim.

T: E agora, que tal outra situação que você já mencionou - seu trabalho voluntário. Mais uma vez, temos duas estudantes universitárias. Esta é a primeira experiência delas como tutora. Elas não estão seguras quanto ao que fazer porque nunca fizeram isso antes. Uma procura ajuda, a outra não, mas continua a ter dificuldades. Quem é mais competente?

$\mathrm{P}:$ (hesitante) A que procura ajuda?

T: Você tem certeza?

P: (Pensa por um momento) É. Não é um sinal de competência simplesmente lutar contra as dificuldades se você pode obter ajuda e fazer melhor.

T: O quanto você acredita nisso?

P: Bastante $-80 \%$.

T: E como estas duas situações - terapia e ajuda no trabalho voluntário aplicam-se a você? 
P: Eu acho que se aplicam.

T: Então anote alguma coisa a respeito disso... vamos chamar a primeira ideia de "antiga crença" - então, o que você disse?

P: Se eu pedir ajuda, eu sou incompetente.

T: O quanto você acredita nisso agora?

P: Menos. Talvez $40 \%$.

T: Ok, escreva $40 \%$ ao lado dela.

P: (Faz isso)

T: Agora escreva "nova crença". Como você escreveria isso?

P: Se eu pedir ajuda, não sou incompetente?

T: Você não parece convencida. Seria melhor se dissesse "Se eu pedir ajuda quando for razoável, isso será um sinal de competência"?

P: Sim. (Escreve isso)

T: O quanto você acredita na nova crença agora?

P: Muito... (Lê e pondera sobre a nova crença)

Talvez de 70 a $80 \%$. (Anota isso) ...” (p.236-237)

Já a diferença entre um método socrático e um não socrático pode ser observada conforme Knapp ${ }^{12}$ (2004): Neste exemplo, em uma sessão de terapia, a paciente diz "sinto que não sou uma boa mãe, pois gritei com meu filho quando ele não estava se comportando bem". Para questionar a paciente socraticamente, o terapeuta pode escolher uma ou mais das formulações seguintes, a fim de guiá-la na descoberta de evidências que comprovem se esta afirmação é verdadeira ou não:

"- "O que é mesmo ser uma boa mãe? Dessas características, enumeradas por você, do que é ser uma boa mãe, quais você possui?"

- "Quem você considera uma boa mãe? Por que [essa pessoa] é considerada uma boa mãe?"

- "O que uma boa mãe faz após ter gritado com o filho e se sentido mal com isso?"

- "O que você acha que estava sentindo antes de gritar com seu filho o que você acha que estava pensando antes de gritar com seu filho?"

- "As habilidades que uma pessoa necessita para ser uma boa mãe já nascem com ela, ou a pessoa pode aprender a ser uma boa mãe? "'”.

Do mesmo modo, o caso de um questionamento nãosocrático na mesma situação, se daria da seguinte forma:

“_ "E daí se você grita com seus filhos? Todo mundo faz isso."

- "Por que você está sendo tão dura consigo mesma?"

- "Seus pais nunca gritaram com você? "”'(p.31).

\section{DISCUSSÃO}

Por meio do exposto neste artigo, é possível observar que o modelo terapêutico cognitivo-comportamental visa primordialmente envolver ativamente o paciente no processo de aprendizagem, de modo que este seja incitado à prática de "pensar sobre o pensamento" e, assim, provocar insights.

Desta forma, o paciente inserido nesta abordagem terapêutica é constantemente estimulado a segmentar seu sofrimento psíquico para autoexploração, em consequência de seus aprendizados adquiridos.

Assim sendo, a técnica do questionamento socrático apesar de simples e polivalente, abrange inúmeras vantagens nesse processo, compreendendo desde a intensificação da relação terapêutica, estimulação da indagação, maior entendimento das cognições e comportamentos importantes, bem como, a acessão do engajamento ativo do paciente na terapia.
Além do mais, ao se utilizar essa técnica, os benefícios obtidos além de serem conservados, são acrescidos, de forma que o paciente tende a ganhar mais espaço nas sessões e em todo o processo terapêutico e obtêm-se maior redução da possibilidade do terapeuta impor suas ideias e conceitos. O que não passa a se tornar uma dificuldade, posto que o sujeito é equipado com as habilidades necessárias para lidar com eventuais problemas que possam surgir.

No entanto, pode-se citar como ponto negativo o dispêndio de tempo e paciência, já que o uso de tal técnica requerer comprometimento tanto do paciente quanto do terapeuta em função dos registros constantes dos pensamentos disfuncionais e perguntas livres - visando identificar, questionar e avaliar os mesmos na busca de evidencias para tomada de decisões racionais e desenvolvimento de novas estratégias, para lidar com as dificuldades e estabelecer uma mudança cognitiva duradoura.

Apesar de esta não ser a única desvantagem avaliada, pois para um bom andamento terapêutico é necessário que as técnicas se complementem para uma melhor compreensão da situação trabalhada, à vista disto, quando se elabora perguntas do questionamento socrático e estas não são suficientes para modificação dos seus pensamentos, os terapeutas precisam usar outros tipos de questões e técnicas como forma de apurar se os pacientes têm crenças que interferem no processo de avaliação dos seus pensamentos ${ }^{13}$.

Mesmo assim, a terapia cognitiva não é apenas um punhado de técnicas cognitivas e comportamentais tiradas do instrumental terapêutico disponível. Segundo Beck ${ }^{16}$, o modelo cognitivo não é definido pela variedade de técnicas que são empregadas, mas sim, na ênfase que se é dada ao papel dos pensamentos na causa e na manutenção dos transtornos pelo terapeuta.

Em função disso, assim como em qualquer técnica, o questionamento socrático também possui limitações, isto é, o uso de tal técnica se mostra pouco eficaz com pacientes que se recusam participarem nas atividades no processo de tratamento, mesmo que essa resistência já tenha sido trabalhada por meio das técnicas cognitivas, fato que não se deve a qualidade da técnica, mas pela resistência do paciente $^{17}$.

É necessário frisar ainda que o uso dessa técnica, semelhantemente a pacientes com contraindicações á TCC, não se aplica a casos de pacientes com demência avançada (outros transtornos amnésicos severos e estados de confusão mais transitórios, como delirium ou intoxicação por drogas) e para pacientes com quadros clínicos que comprometem extremamente o envolvimento em uma relação terapêutica colaborativa e baseada na confiança, como, o transtorno de personalidade antissocial grave. Sendo que essas condições não se limitam apenas a esse tipo de psicoterapia $^{3}$.

\section{CONSIDERAÇÕES FINAIS}

Por fim, apesar das divergências, se o questionamento socrático for realizado corretamente, ele terá forte impacto sobre a organização cognitiva do paciente, promovendo que o mesmo desenvolva uma autoexploração inquisitiva, contanto que, o paciente ainda permanece com memória e capacidade de aprendizado preservados, se identifique com o modelo cognitivo e tenha boa habilidade de resoluções de problemas. 


\section{REFERÊNCIAS}

1. Knapp P, Isolan L. Abordagens psicoterápicas no transtorno bipolar. Rev Psiq Clín. 2005; 32(supl 1):98104.

2. Wright JH, Basco MR, Thase ME. Aprendendo a terapia cognitivo-comportamental: um guia ilustrado. Porto Alegre: Artmed, 2008.

3. Beck, JS. Terapia cognitiva: teoria e prática. Porto Alegre: Artes Médicas, 1997.

4. Knapp P. Princípios da Terapia Cognitiva. In: Knapp P. (org.) Terapia cognitivo-comportamental na prática psiquiátrica. Porto Alegre: Artes Médicas, 2004.

5. Yano Y, Meyer SB, Tung TC. Modelos de tratamento para o transtorno do pânico. Estud Psicol. 2003; 20(3):125-34.

6. Bennett-Levy J, Butler G, Fermell M, Hackman A, Mueller M, Westbrook D. The Oxford guide to behavioural experiments in cognitive therapy. Oxford, UK: Oxford University Press. 2004; p.1- 20.

7. Beck AT, Rush AJ, Shaw BF, Emery G. Terapia Cognitiva da Depressão. Porto Alegre: Artmed, 1997.

8. Clark DA, Beck AT, Alford HÁ: Scientific Foundations of Cognitive Theory and Therapy of Depression. New York: Wiley, 1999.

9. Bahls SC, Navolar ABB. Terapia cognitivocomportamentais: conceitos e pressupostos teóricos. Rev Eletrônica Psicol. 2004; (4). Disponível em: www.utp.br/ psico.utp.online. Acesso em: 15 jan. 2017.

10. Otto MW, Jones JC, Craske MG, Barlow DH. Stopping anxiety medication: panic control therapy for benzodiazepine discontinuation: therapist guide. New York: Psychological Corporation; 1996.

11. Stallard P. Guia do terapeuta para os bons pensamentosbons sentimentos: utilizando a terapia cognitivocomportamental com crianças e adolescentes. Porto Alegre: Artmed, 2007

12. Knapp P. Principais Técnicas. In: KNAPP P. (org.) Terapia cognitivo-comportamental na prática psiquiátrica. Porto Alegre: Artes Médicas, 2004.

13. Beck JS. Terapia cognitiva para desafios clínicos: o que fazer quando o básico não funciona. Trad. Sandra Moreira de Carvalho. Porto Alegre: Artmed, 2007.

14. Cordioli AV. A terapia cognitivo-comportamental no transtorno obsessivo-compulsivo. Rev Bras Psiquiatr. 2008; 30(2):65-72.

15. Beck JS. Terapia cognitivo-comportamental: teoria e prática. Trad. Sandra Mallman da Rosa. $2^{\circ}$ ed. Porto Alegre: Artmed, 2013.

16. Beck AT. Cognitive therapy and the emotional disorders. New York: International Universities Press, 1976.

17. Salkovisks PM, Kirk J. Distúrbios obsessivos. In: Hawton K, et al. Terapia cognitivo-comportamental para problemas psiquiátricos: um guia prático. São Paulo: Martins Fontes, 1997.

\section{CONFLITO DE INTERESSES}

Os autores declaram não haver conflitos de interesse.

\section{AUTOR PARA CORRESPONDÊNCIA}

\section{Camila Elidia Messias dos Santos}

kmila_messias@hotmail.com

Submetido em 26/01/2017

Aceito em 03/04/2017 